\title{
Determination of Pathloss Exponent Using Gsm Signal in Orhuwhorun Environ, Delta State
}

\author{
${ }^{1}$ Idim, A. I and ${ }^{2}$ Anyasi F.I \\ ${ }^{l}$ Department of Electrical and Electronic Engineering, Petroleum Training Institute, P.M.B 20, Effurun, Delta \\ State, Nigeria. \\ ${ }^{2}$ Department Electrical and Electronic Engineering, Ambrose Alli University, P.M.B 14, Ekpoma. Edo State,
} Nigeria.

\begin{abstract}
Interest involves the determination of path loss exponent in Orhuwhorun environs, Delta state, Nigeria.This work is to provide a propagation model that can be used to accurately determine path loss in Orhuwhorun, since such was not previously available. In this research, measurements of two existing GSM Operators' signals level were made outside and inside three selected buildings- concrete, block and mud which represent the prevalent building types in Orhuwhorun, Delta State, Nigeria. A Samsung Galaxy GT-35000 mobile phone with RF signal tracker software installed in it was used and the results shows an average loss of $10.62 \mathrm{dBm}, 4.20 \mathrm{dBm}$ and $5.11 \mathrm{dBm}$ for the concrete, block and mud buildings, respectively with a corresponding average path loss exponent of 3.67, 3.86 and 3.60. The modeled path loss varies with distance and environment. This result will help service providers for future site-specific planning.
\end{abstract}

\section{Introduction}

Any communication system can be viewed as a link between a source and a destination, where information is sent from the source and received at the destination. Of all the communications services available today, wireless services are having the most dramatic impact on our personal and professional lives, enhancing personal productivity, mobility and security (Muller and Nathan, 2003).

Of significant importance to the Nigerian market is the global mobile communication system popularly called GSM (GSM-1800) which operates in the $1800 \mathrm{MHz}$ frequency band. GSM was first introduced in 2001 when MTN Nigeria Limited and Econet Wireless Nigeria Limited (now Airtel) were licensed and consequently started operations. As at today the GSM Operators in the country include MTN Nigeria Limited and Airtel Nigeria, Limited Globacom Nigeria Limited and and Etisalat. With the advent of GSM in Nigeria telecommunication services have been brought nearer to the average individual (Adewoye, 2010).

The mobile radio channel however places fundamental limitations on the performance of wireless communication system as the transmission path between the transmitter and receiver antennas can vary from simple line-of-sight to one that is severely obstructed by buildings, mountains, and foliage. Thus mobile radio channels are not easily predictable, as even the speed of motion impacts how rapidly the signal fades as the mobile terminal moves in space. They are extremely random, and as such do not offer easy analysis (Rappaport, 2003). Propagation modeling is the common approach to predicting the mobile radio behaviour. The most widely used models are classified as empirical models. These are based on extensive field measurements which are used to predict the average path loss along the radio path from the base station antenna to the mobile antenna (Feher, 1991). They assume straight propagation from transmitter to receiver, regardless of any obstacles, such as buildings and walls. They are more widely used because they offer short computation times, even though they are not always $100 \%$ accurate. The accuracy of the propagation model on which any network was built to a large extent determines the radio coverage of any wireless network and to predict the accuracy of the model real-time measurement must exhaustively be taken from the service area, in which the network was designed. (Emagbetere and Edeko, 2009). The major driving force for this research, therefore, is the need to provide propagation model that is best suitable for predicting indoor GSM reception in Orhuwhorun, since no such models currently exist. By extrapolation the developed model can be used in other regions with similar buildings and terrain.

For a given building the average building penetration loss may be computed using equation (1) (Caluyo and Cruz, 2011).

$\mathrm{ABL}(\mathrm{dBm})=$ Mean $\mathrm{S}_{\text {out }}(\mathrm{dBm})-$ Mean $\mathrm{S}_{\text {in }}(\mathrm{dBm})$

Where ABL is the Average Penetration Loss in $\mathrm{dBm}$, Mean $\mathrm{S}_{\text {out }}$ is Mean signal level outside the building in $\mathrm{dBm}$ and Mean $\mathrm{S}_{\mathrm{in}}=$ Mean signal level inside the building in $\mathrm{dBm}$.

Path loss represents the communication system attenuation. It is defined as (Feher, 1995).

$$
\mathrm{PL}=\frac{\mathrm{P}_{\mathrm{T}}}{\mathrm{P}_{\mathrm{R}}}
$$


Alternately

$$
P L(d B)=P_{T}(d B)+P_{R}(d B)
$$

Where PL is the path loss, $\mathrm{P}_{\mathrm{T}}$ is the Transmitter antenna power and $\mathrm{P}_{\mathrm{R}}$ is the Receiver antenna power.

Friis Free Space Model

The path loss (in decibel) for the Friis free space model is given by

$$
P L(d B)=-10 \log \left[\frac{G_{t} G_{r} \lambda^{2}}{(4 \pi)^{2} d^{2}}\right]
$$

Where $P_{t}=$ the transmitted power, $P_{r}(d)=$ the received power which is a function of the transmitterreceiver separation, $\mathrm{G}_{\mathrm{t}}=$ the transmitter antenna gain, $\mathrm{G}_{\mathrm{r}}=$ the receiver antenna gain, $\mathrm{d}=$ the transmitter-receiver separation distance in meters and $\lambda=$ the wavelength in meters.

Typically used for unobstructed line of LOS signal path, the simplified model expresses path loss as equation (5) (Armogun et al, 2008).

$$
\mathrm{PL}_{\mathrm{FS}}=32.45+20 \log 10(\mathrm{~d})+20 \log 10(\mathrm{f})[\mathrm{dB}]
$$

Where $\mathrm{PL}_{\mathrm{FS}}$ is the Path loss, $\mathrm{d}$ is the transmitter-receiver separation distance in $\mathrm{Km}$ and $\mathrm{f}$ is the frequency in $\mathrm{MHz}$.

\section{Materials And Methods}

A case study method was used on two different buildings, a concrete and the other, block. A Samsung Galaxy phone, with RF Signal Tracker software installed in it, was used for this purpose and the results obtained were compared

\section{Description of Measurement Sites}

The measurement sites were concrete slab (C1), block (B1) and mud (M1) bungalow residential buildings, all located in Orhuwhorun, a sub-urban area in Udu LGA of Delta state, Nigeria. Orhuwhorun is east of the oil rich city of Warri as shown in figure 1. Different views of the measured sites are shown in figures 3-4 and their descriptions in Table 1.

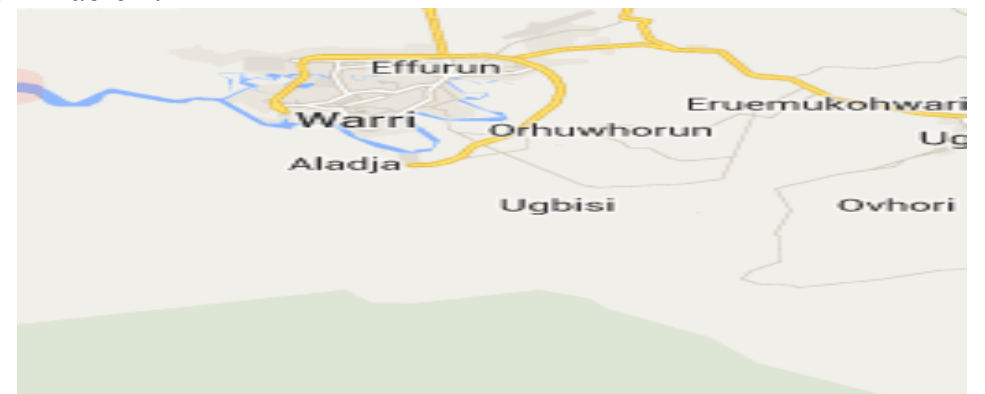

Figure 1 Map showing part of Delta South, Nigeria where Orhuwhorun is located

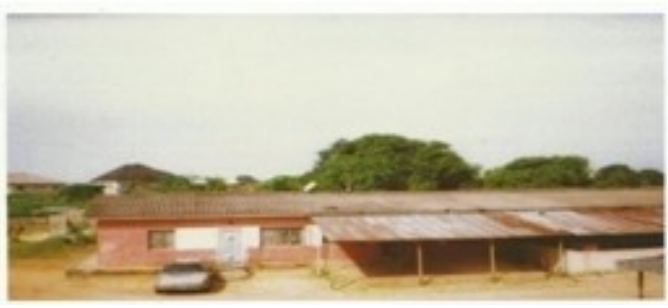

Figure 2(a) Outside view of Site C1

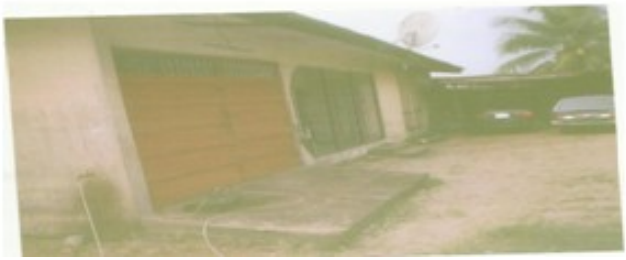

Figure 3 (a) Outside view of Site B1

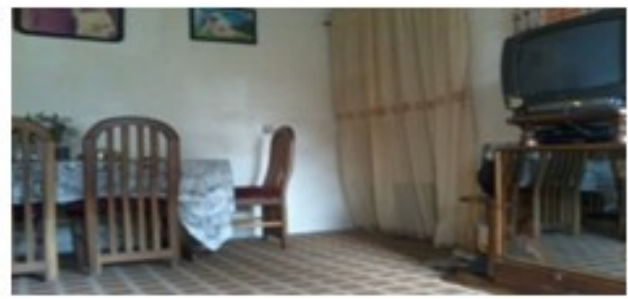

Figure 2(b) Inside view of Site C1

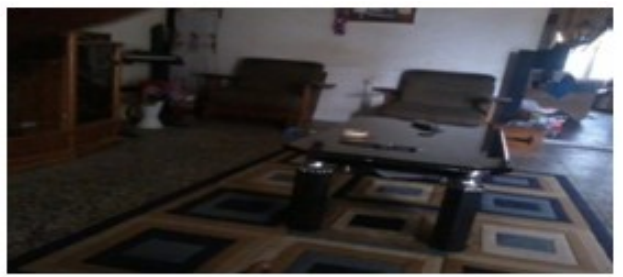

Figure 3 (a) Inside view of Site B1 


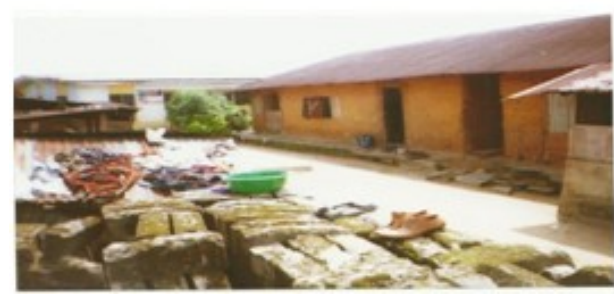

Figure 4(a) Outside view of Site M1

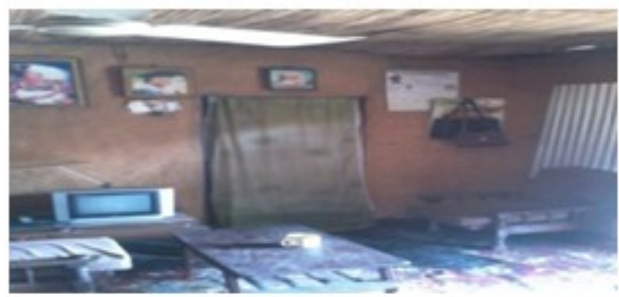

Figure 4(b) Inside view of Site M1

Table1: Measurement Site Description

\begin{tabular}{|l|l|l|l|}
\hline Building & C1 & B1 & M1 \\
\hline Wall Type & $\begin{array}{l}\text { Concrete slab with embedded } \\
\text { steel rods }\end{array}$ & $\begin{array}{l}\text { Moulded cement and sharp sand } \\
\text { mixture block }\end{array}$ & $\begin{array}{l}\text { Mud with wooden and } \\
\text { bamboo frame }\end{array}$ \\
\hline Building Dimension & $33 \mathrm{~m} \times 22.2 \times 3.4 \mathrm{~m}$ & $15.44 \times 12.06 \times 2.84 \mathrm{~m}$ & $19.20 \mathrm{~m} \times 6.76 \mathrm{~m} \times 2.44 \mathrm{~m}$ \\
\hline Wall thickness & $17.79 \mathrm{~cm}$ & $17.79 \mathrm{~cm}$ & $17.79 \mathrm{~cm}$ \\
\hline Distance to fence & None & $3.1 \mathrm{~m}$ minimum & None \\
\hline Surrounding Vegetation & Sparse & Very sparse & None existent \\
\hline $\begin{array}{l}\text { Surrounding Buildings } \\
\text { Density }\end{array}$ & Sparse & Medium & Very high \\
\hline Roof Type & Asbestos & Asbestos & Corrugated iron \\
\hline Room Dimension & $4.14 \mathrm{~m} \times 4.14 \mathrm{~m}$ & $10.7 \mathrm{~m} \times 4.5 \mathrm{~m}$ & $4.14 \mathrm{~m} \times 4.14 \mathrm{~m}$ \\
\hline $\begin{array}{l}\text { No of Windows in Room } \\
\text { Type }\end{array}$ & $1 /$ Casement & $2 /$ Louvers & $2 /$ Wooden \\
\hline Window Size & $1.2 \mathrm{~m} 1.8 \mathrm{~m}$ & $1.9 \mathrm{~m} \times 0.9 \mathrm{~m}$ & $1.02 \mathrm{~m} \times 0.76 \mathrm{~m}$ \\
\hline No ofDoors/ type & $1 /$ steel pan, 4/wooden & $2 /$ Wooden & $1 /$ wooden \\
\hline Door size & $2.1 \mathrm{~m} \times 1 \mathrm{~m}$ & $1.8 \mathrm{~m} \mathrm{x} 1.14 \mathrm{~m}$ & $1.96 \mathrm{~m} \times 0.76 \mathrm{~m}$ \\
\hline
\end{tabular}

\section{Description of Measurement Tools}

The measurement tool was a Samsung Galaxy GT-35000 Mobile phone with RF Signal Tracker software installed in it. The measurement set-up is shown in figure 5. The RF Signal Tracker is a software, with the capability of giving information on a Base Tranceiver station (BTS) over the air interface. The software comprises amongst others a scale capable of identifying the network Operator, a scale capable of identifying the cell identity, a scale calibrated in decibel $(\mathrm{dbm})$, with which the received signal level of the MS is recorded. Others include a scale calibrated in distance terms $(\mathrm{Km})$, with which the distance of the location of the MS from the BTS is recorded, a scale capable of giving the MS altitude and a scale capable of giving the GPS accuracy (Omorogiwa and Edeko, 2009; https://play.google.com, Retrieved $12^{\text {th }}$ November, 2012).

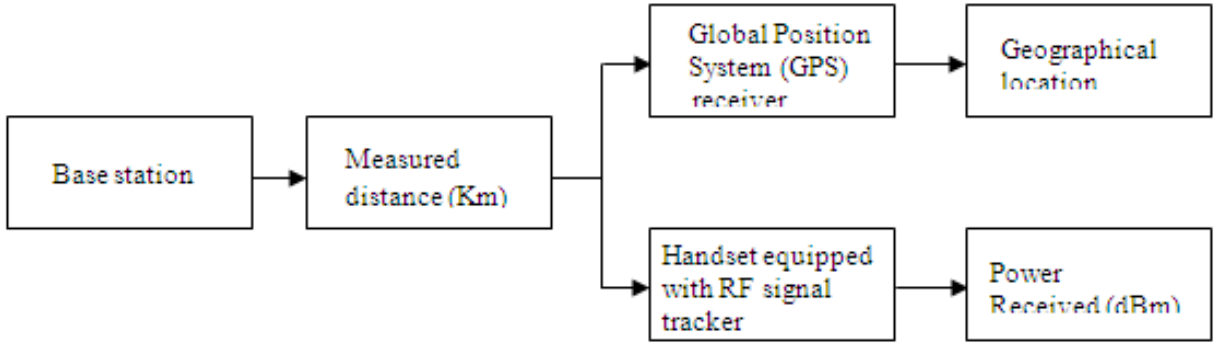

Figure 5 Diagram illustrating measurement set-up

\section{Measurement Result}

The monthly measured average signal levels are tabulated in Tables $2-4$ and the average over the period of six months in Table 5. From the monthly average received signal level the path loss exponent outside each location was computed and the result is tabulated in Table 6 . The average building penetration loss calculated is in Table 5. From the average measured signals at the three locations, the outdoor path loss model proposed for Orhuwhorun is as shown in equation (6)

Where

$$
\mathrm{PL}_{0}=\mathrm{PL}\left(\mathrm{d}_{\mathrm{O}}\right)+30 \log \frac{\mathrm{d}}{\mathrm{d}_{\mathrm{o}}}+\mathrm{me}^{\log \mathrm{d}}
$$

$\mathrm{PL}_{\mathrm{O}}=$ Outdoor Path loss

$\mathrm{d}_{\mathrm{O}}=$ reference distance $=10 \mathrm{~m}$

$\operatorname{PL}\left(\mathrm{d}_{\mathrm{O}}\right)=$ Path loss at a reference distance $=0.057 \mathrm{dBm}$

$\mathrm{d}=$ distance, in meter $(\mathrm{m})$ 
$\mathrm{m}=\mathrm{a}$ positive number

$0.57 \leq \mathrm{m} \leq 1.1$

Values of $m$ are found in Tables 7

The indoor path loss model proposed for Orhuwhorun at all locations is expressed in equation (7).

$\mathrm{PL}_{\mathrm{i}}=$ Indoor Path loss

$$
\mathrm{PL}_{\mathrm{i}}=\mathrm{PL}_{\mathrm{O}}+\mathrm{ABL}
$$

$\mathrm{PL}_{\mathrm{O}}=$ Outdoor Path loss (equation 6)

$\mathrm{ABL}=$ Average building loss (building penetration loss)

Values of ABL are found in Table 5

Table 2 Monthly Measured Signal for Concrete C1

\begin{tabular}{|l|c|l|l|l|l|l|}
\hline \multirow{2}{*}{ Month } & \multicolumn{5}{|c|}{$\begin{array}{c}\text { Average Measured } \\
\text { Monthly Signal (dBm) }\end{array}$} \\
\cline { 2 - 7 } & \multicolumn{3}{|c|}{ Operator A at 472m } & \multicolumn{4}{c|}{ Operator B at 837m } \\
\cline { 2 - 7 } & Outside & Inside & BPL & Outside & Inside & BPL \\
\hline January & -59.46 & -68.50 & 9.04 & -73.93 & -83.71 & 9.78 \\
\hline February & -59.07 & -68.75 & 9.68 & -73.52 & -83.65 & 10.13 \\
\hline March & -58.63 & -68.92 & 10.29 & -73.93 & -84.37 & 10.44 \\
\hline April & -58.39 & -68.99 & 10.60 & -74.30 & -85.50 & 11.20 \\
\hline May & -58.15 & -68.97 & 10.82 & -72.92 & -84.96 & 12.04 \\
\hline June & -57.83 & -69.06 & 11.23 & -73.04 & -85.20 & 12.16 \\
\hline
\end{tabular}

Table 3 Monthly Measured Signal for Block B1

\begin{tabular}{|c|c|c|c|c|c|c|}
\hline \multirow[b]{3}{*}{ Month } & \multicolumn{6}{|c|}{$\begin{array}{c}\text { Average Measured } \\
\text { Monthly Signal (dBm) }\end{array}$} \\
\hline & \multicolumn{3}{|c|}{ Operator A at $542 \mathrm{~m}$} & \multicolumn{3}{|c|}{ Operator B at $759 \mathrm{~m}$} \\
\hline & Outside & Inside & BPL & Outside & Inside & B PL \\
\hline January & -63.06 & -66.97 & 3.91 & -75.26 & -78.48 & 4.02 \\
\hline February & -64.14 & -68.12 & 3.98 & -74.39 & -78.59 & 4.10 \\
\hline March & -62.71 & -66.72 & 4.01 & -73.64 & -78.15 & 4.41 \\
\hline April & -62.78 & -66.79 & 4.01 & -73.34 & -77.94 & 4.50 \\
\hline May & -63.18 & -67.24 & 4.06 & -73.95 & -78.57 & 4.62 \\
\hline June & -63.48 & -67.61 & 4.13 & -75.28 & -80.03 & 4.75 \\
\hline
\end{tabular}

Table 4 Monthly Measured Signal for Mud M1

\begin{tabular}{|l|c|l|l|c|l|l|}
\hline \multirow{2}{*}{\multicolumn{1}{c|}{ Month }} & \multicolumn{5}{|c|}{$\begin{array}{c}\text { Average Measured } \\
\text { Monthly Signal (dBm) }\end{array}$} \\
\cline { 2 - 7 } & \multicolumn{3}{|c|}{ Operator A at 477.9m } & \multicolumn{3}{c|}{ Operator B at 582.0 m } \\
\cline { 2 - 7 } & Outside & Inside & BPL & -69.99 & -75.81 & 5.82 \\
\hline January & -62.79 & -67.60 & 4.81 & -70.47 & -76.11 & 5.64 \\
\hline February & -62.72 & -67.48 & 4.76 & -70.38 & -75.81 & 5.43 \\
\hline March & -62.91 & -67.74 & 4.81 & -70.54 & -76.00 & 5.46 \\
\hline April & -62.80 & -67.55 & 4.75 & -70.83 & -76.27 & 5.46 \\
\hline May & -62.71 & -67.53 & 4.82 & -71.05 & -75.89 & 4.84 \\
\hline June & -62.33 & -67.06 & 4.73 & & Inside \\
\hline
\end{tabular}

Table 5: Average Measured Signal

\begin{tabular}{|c|c|c|c|c|c|}
\hline \multirow{2}{*}{ BUILDING } & \multirow[t]{2}{*}{ Distance (m) } & \multirow{2}{*}{ Operator } & \multicolumn{3}{|c|}{$\begin{array}{l}\text { Average Measured } \\
\text { Signal }(\mathrm{dBm})\end{array}$} \\
\hline & & & Outside & Inside & ABL \\
\hline $\mathrm{C} 1$ & 472.0 & $\mathrm{~A}$ & -58.59 & -68.87 & 10.28 \\
\hline $\mathrm{C} 1$ & 837.0 & $\mathrm{~B}$ & -73.61 & -84.57 & 10.96 \\
\hline $\mathrm{B} 1$ & 542.0 & $\mathrm{~A}$ & -63.22 & -67.24 & 4.02 \\
\hline $\mathrm{B} 1$ & 759.0 & $\mathrm{~B}$ & -74.43 & -78.81 & 4.40 \\
\hline M1 & 477.9 & $\mathrm{~A}$ & -62.71 & -67.49 & 4.78 \\
\hline M1 & 582.0 & $\mathrm{~B}$ & -70.54 & -75.98 & 5.44 \\
\hline
\end{tabular}


Determination of Pathloss Exponent Using Gsm Signal in Orhuwhorun Environ, Delta State

Table 6: Average Value Of Path Loss Exponent

\begin{tabular}{|c|c|c|c|}
\hline BUILDNG & \multicolumn{3}{|c|}{ PATH LOSS EXPONENT, n } \\
\hline TYPE & OPERATOR A & OPERATOR B & AVERAGE \\
\hline C1 & 3.50 & 3.83 & 3.67 \\
\hline M1 & 3.73 & 3.99 & 3.86 \\
\hline B1 & 3.64 & 3.96 & 3.80 \\
\hline
\end{tabular}

Table 7: Average Value Of Penetration Loss Of Buildings C1 And Average Values Of m

\begin{tabular}{|c|c|c|c|c|}
\hline BUILDING & \multicolumn{3}{|c|}{ VALUE OF m } & $\begin{array}{c}\text { MEAN VERAGE } \\
\text { PENETRATION LOSS } \\
\text { ABL (dBm) }\end{array}$ \\
\hline C1 & OPERATOR A & OPERATOR B & AVERAGE & 10.62 \\
\hline M1 & 0.57 & 0.85 & 0.71 & 5.11 \\
\hline B1 & 0.84 & 1.10 & 0.97 & 4.21 \\
\hline
\end{tabular}

Plots of the outdoor and indoor models for different values of $d$ are shown in figure 6- 11.
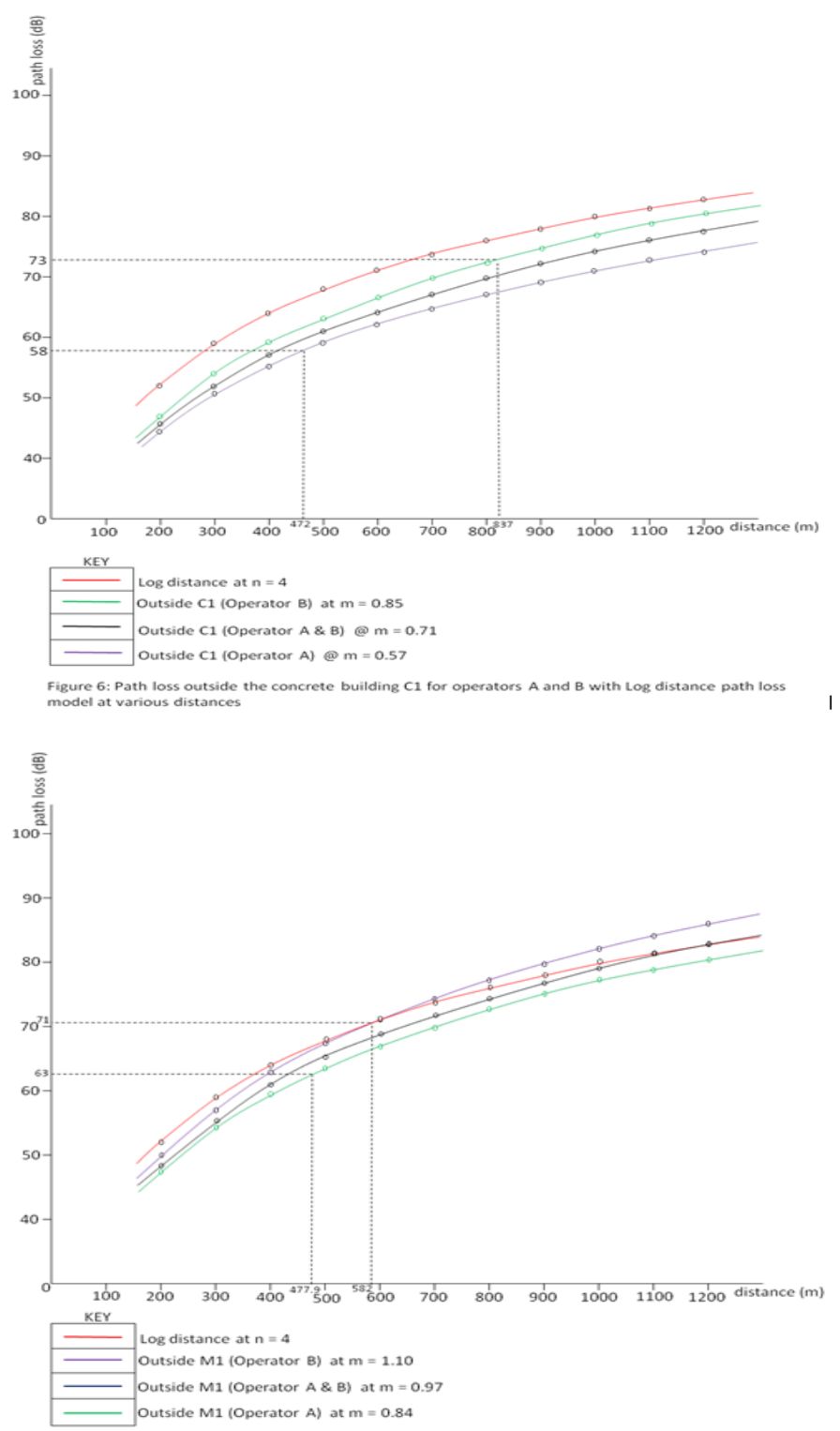

Figure 7: Path loss outside the Mud building M1 for operators $A$ and $B$ with Log distance 


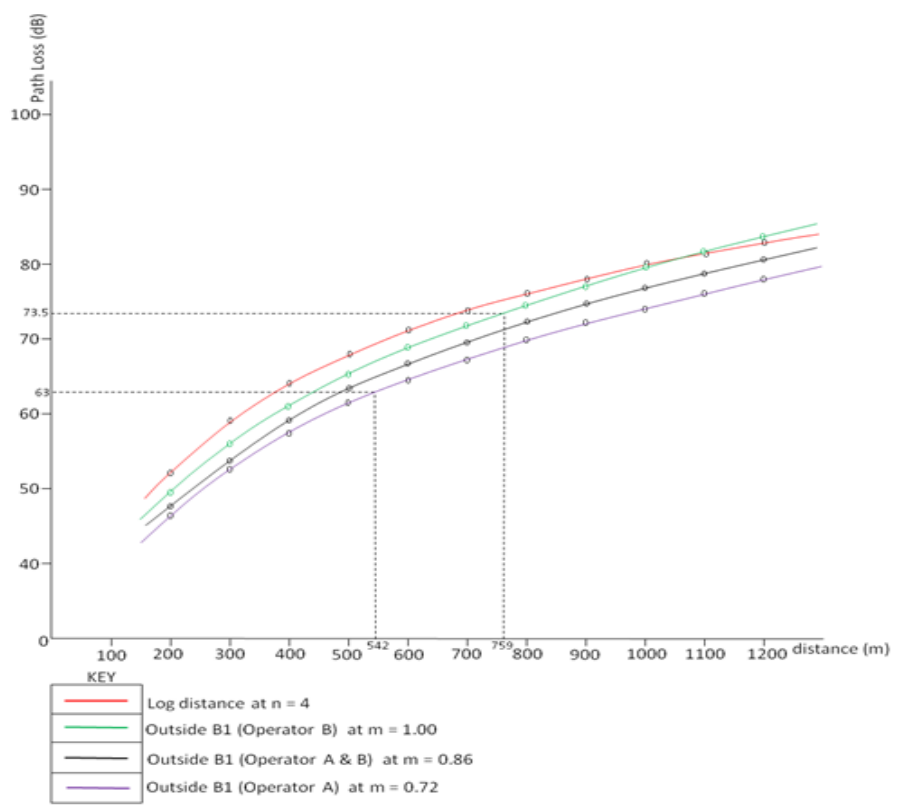

Figure 8: Path loss outside the Block building B1 for operators A and B with Log distance path loss model at various distances

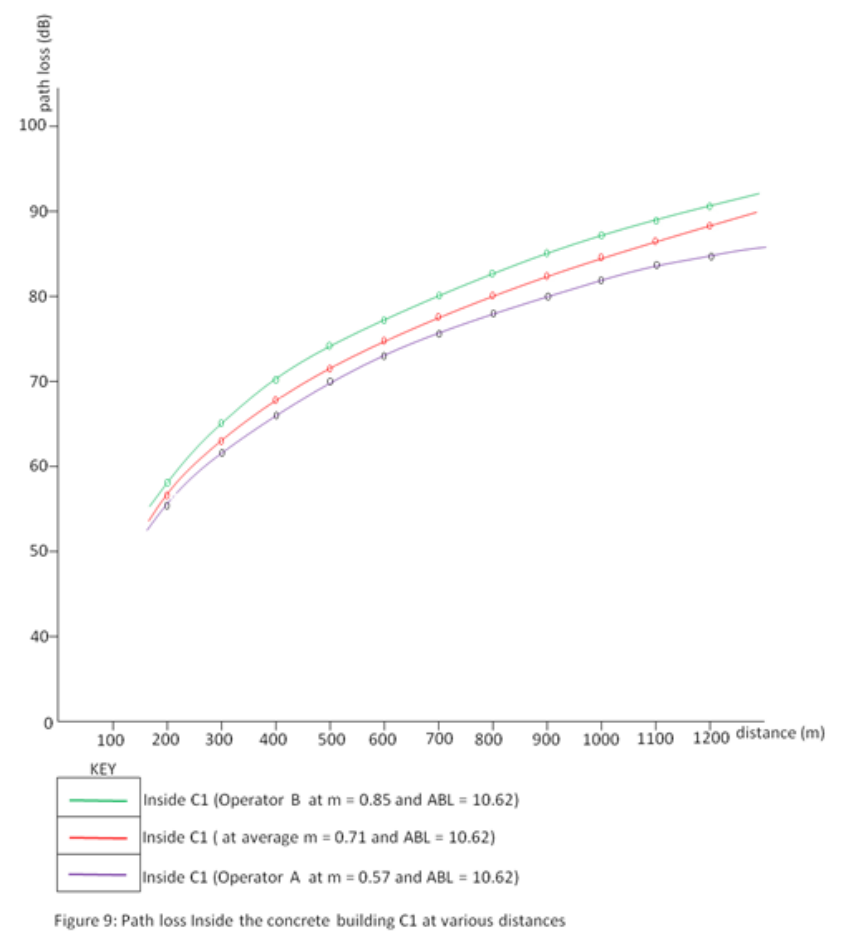



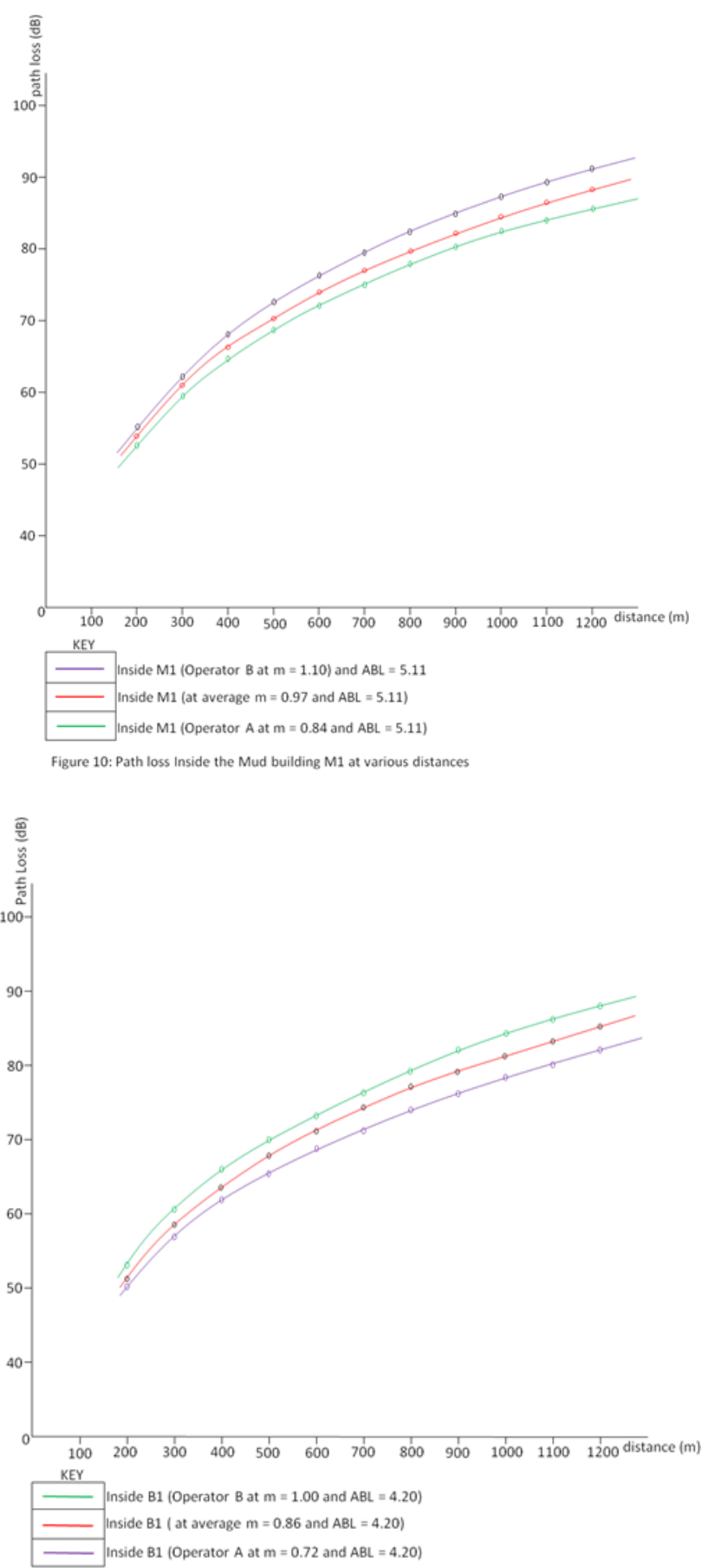

Figure 11 Path loss outside the Block building B1 for operators A and B with Log distance path loss model at various distances

Path Loss

\section{Discussion Of Results}

Plots of path loss outside each of the three buildings obtained from the generated model shown in figures 1-3 indicate a loss of $30 \mathrm{~dB} /$ decade outside $\mathrm{C} 1$ using operator A signals and $33 \mathrm{~dB} /$ decade using operator $\mathrm{B}$ signals. These values are $1.07 \mathrm{dBm}$ lower and $1.88 \mathrm{dBm}$ higher, respectively when compared with the $31.12 \mathrm{dBm} /$ decade obtained for similar distances using log- distance path loss model. Comparatively the loss using Operator B is higher than that of Operator A by $3.29 \mathrm{dBm}$. The average between Operator A and Operator B shows $31 \mathrm{~dB} /$ decade loss. $58.0 \mathrm{dBm}$ loss at the measured distance of $472 \mathrm{~m}$ of Operator A signals and 73.0 $\mathrm{dBm}$ loss at the measured distance of $837 \mathrm{~m}$ of Operator B signals, respectively can be observed from Figure 1 .

Outside M1 (the mud building) a loss of $32.6 \mathrm{dBm} /$ decade and $36 \mathrm{dBm} / \mathrm{decade}$ ( figure 2) are obtained from Operator A and Operator B signals, respectively. A difference of $3.4 \mathrm{dBm}$ exists between them. When compared with the log-distance path loss model for a similar environment these are $1.6 \mathrm{dBm}$ and $5 \mathrm{dBm}$ higher, 
respectively. The average between the two Operators shows $34.8 \mathrm{~dB} /$ decade loss. At the measured distance of $477.9 \mathrm{~m}$ of Operator A signal the plot shows a path loss of approximately $63.0 \mathrm{dBm}$. A loss of $71.0 \mathrm{dBm}$ at the measured distance of $582 \mathrm{~m}$ of Operator B signals is observed.

In Fig. 3 path loss of $32.5 \mathrm{dBm} /$ decade and $34.5 \mathrm{dBm} /$ decade losses are observed outside $\mathrm{B} 1$ (the block building) for Operator A and Operator B signals respectively. A 2.0 dBm difference is observed between them. These are $1.5 \mathrm{dBm}$ and $3.5 \mathrm{dBm}$ higher, respectively when compared with log distance path loss model at similar distances. The average losses between the Operators show $33.3 \mathrm{~dB} / \mathrm{decade}$. At the measured distance of $542 \mathrm{~m}$ of Operator A signals a path loss of $63.0 \mathrm{dBm}$ is observed from the plot and $73.5 \mathrm{dBm}$ is observed at the measured distance of $759 \mathrm{~m}$ of Operator B signals.

Comparing the values from Operator A and Operator B signals average values of $31 \mathrm{dBm} / \mathrm{dec}$ de, $34.8 \mathrm{dBm} / \mathrm{decade}$ and $33.3 \mathrm{dBm} /$ decade are obtained for the path loss outside the concrete, mud and block buildings, respectively. That the highest loss is obtained outside the mud building is an indication of the fact that buildings in this part of Orhuwhorun are more cluttered than in the parts where the concrete and the block buildings, respectively are located. Buildings and other structures are relatively more cluttered where the block building is than where the concrete building is located.

\section{Building Clutter Factor}

Outside the concrete building the values of $\mathrm{m}$ were 0.57 and 0.85 for Operator A and Operator B signals. The values of $\mathrm{m}$ for outdoor mud were 0.84 and 1.1 for Operators $\mathrm{A}$ and $\mathrm{B}$, respectively, whereas outside the block building 0.72 and 1.0 were obtained as $\mathrm{m}$. The highest values of $\mathrm{m}$ for both operators were obtained outside the mud building where buildings are cluttered together, while the least values of $\mathrm{m}$ were obtained outside the concrete building where buildings are least cluttered. These are in agreement with the average path loss and an indication that $\mathrm{m}$ is an environmental factor. Hence $\mathrm{m}$ is referred to here as building clutter factor, in this work.

The modeled indoor path loss as shown in the plots of Figs. 4 - 6 differs from the outdoor model at all the locations by the building penetration loss, ABL. As can be seen the graphs of $\mathrm{C} 1$ in Fig. 4 are shifted above their counterparts in Fig. 1 by $10.62 \mathrm{dBm}$. It is also noticed that the graphs of M1 in Fig. 5 are shifted above their counterparts in Fig. 2 by $5.11 \mathrm{dBm}$, likewise the graph of B1 in Fig. 6 which is also seen to be shifted above their counterparts in Fig. 3 by $4.2 \mathrm{dBm}$.

\section{Path Loss Exponent}

The average values of path loss exponent outside the three buildings in Orhuwhorun were summarized in Table 3. The least value of 3.67 was obtained outside the concrete building $\mathrm{C} 1$, where houses are relatively spaced while the highest value of 3.86 was obtained outside the mud building where buildings are clustered together. The value of $\mathrm{n}$ at location B1 is very close to that of MI even though houses are not as clustered here as location. Their closeness is most likely due to the fences separating one building from the other.

These values of path loss exponent are in agreement with theoretical values of between 3 and 5 for such environments [Rappaport, 2003]. These also agree with the value of 3.84 reported for suburban areas in Lee's work [Adenike, 2010].

\section{Building Penetration Loss}

Building penetration loss values obtained for the three buildings are shown in Table 6 . The concrete building wall has the highest value of 10.62 while the least value of 4.20 was obtained for the block wall. These values attest to the fact that the type of construction materials affects GSM signals levels inside buildings [Rappaport, 2003] [Walker, 1983] [Caluyo, Cruz, 2011]. The mud building wall penetration loss of 5.11 is very close to that of the block wall. This shows that these two construction materials are almost similar from the view point of radio signals. The concrete wall value is significantly greater than the other two. This is most likely due to the fact that mud and block are more porous than concrete. The value of $10.62 \mathrm{dBm}$ obtained for the concrete building is $2.78 \mathrm{dBm}$ lower than the $13.4 \mathrm{dBm}$ reported by Turkmani [Turkmani, 1992] measured on the ground floor of a building at $1800 \mathrm{MHz}$ in. The difference is most likely due the differences in the type and thickness of the wall as well as the window size of of the two buildings. Besides the building under consideration is a bungalow whereas the building measured by Turkmani is a storey building. The measured concrete building penetration loss is less than the $13 \mathrm{dBm}$ maximum value reported by Rappaport [Rappaport, 1991] for concrete at $1300 \mathrm{MHz}$. The difference may be accounted for by the fact that penetration loss decreases with increasing frequency as reported by researchers [Turkmani, 1992].

Penetration loss of $4.20 \mathrm{dBm}$ obtained for the block wall at $1800 \mathrm{MHz}$ under consideration is lower than the $13 \mathrm{dBm}$ minimum for concrete block wall reported by researchers at $1300 \mathrm{MHz}$.. This is in agreement with researchers' observation that penetration loss decreases with increasing frequency. The low value can also be accounted for by the fact that the block wall being studied is much more porous than the concrete block wall 
reported by Rappaport [Rappaport, 1991].

The penetration loss of $5.11 \mathrm{dBm}$ obtained for the mud building wall is $0.91 \mathrm{dBm}$ greater than the block wall loss. The higher value obtained for mud is most likely due to the wooden windows which has a higher compared with glass louver window.

\section{Conclusion}

The result of this work shows that as a mobile unit is moved from outside to inside a building the path loss increases and that penetration loss of GSM signals is a function of the building wall type and that the loss through a concrete wall is higher than the loss through a block wall.

\section{References}

[1]. Adenike, F. (2010) Macrocell Path Loss Model for Tropical Savannah Transcampus Journal of Research in National Development 8(1). Retrieved from http://www.transcampus.org, $11^{\text {th }}$ November, 2012

[2]. Adewoye, J. O; Obasa, K. A.(2010) Impact of Global System for Mobile Communication on Small Business Development, Journal of Management and Society 1(2) 44-50.

[3]. Armogun V., Soyjuadah K.M.S.,Mohamudally N., Forgaty T.,( 2008), Comparative Study of Path Loss Using Existing models for digital television broadcasting for summer season in the north mauritus, IEE, The third advanced international conference on telecommunications, (AICT'10) 34.

[4]. Beasley, J, S and Miller, G. M.,(2005). Modern Electronics Communication, $8^{\text {th }}$ ed. Prentice-Hall Inc, Upper Saddle River, New Jersey, USA, 515-516 pp.

[5]. Caluyo, F. S. and Dela Cruz, J. C. (2011), Penetration Loss of Doors and Windows inside Residences using ISDB-T Digital Terrestrial Television Signal at $677 \mathrm{MHz}$, Proceedings of the World Congress on Engineering and Computer Science, San Francisco, USA 2: 890-894.

[6]. Emagbetere, J.O. and Edeko, F.O.,(2009), Measurement Validation of Hata - Like Models for Radio Propagation Path Loss in Rural Environment at $1.8 \mathrm{GHz}$, Journal of Mobile Communication, 3:17 - 21 .

[7]. Rappaport, T. S. (2003). Wireless Communications- Principles and Practice, $2^{\text {nd }}$ ed. Pearson Education PTE Ltd, Singapore, 105$167 \mathrm{pp}$.

[8]. Famoriji John Oluwole and Olasoji Yekeen Olajide (2013). Radio frequency propagation mechanisms and empirical models for Hilly Areas, International Journal of Electrical Computer Engineering(IJECE), 3(3)372-376.

[9]. Feher and Kamilo,(1995), Wireless Digital communications: Modulation and Spread Spectrum Applications, $1^{\text {st }}$ ed. New Jersey: Prentice-Hall, Inc., 66-67 pp.

[10]. Horikoshi, J; Tanaka, $\mathrm{K}$ and Morinaga,T (1986) $1.2 \mathrm{GHz}$ band wave propagation measurements in concrete building for indoor radio communications, IEEE Trans. Vehicular. Technology 35(4), $146-152$.

[11]. Isabona Joseph and Konyeha C. C. (2013), Experimental Study of UMTS Radio Signal Propaggation Characteristics by Field Measurement, American Journal of Engineering Research (AJER), 99-106.

[12]. Kennedy and Davies, (2003), Electronics Communication Systems, $4^{\text {th }}$ ed. New Delhi: Tata Mc Graw-Hill Publishing Company. $229-246 \mathrm{pp}$.

[13]. Muller, Nathan J.,(2003). Wireless A- Z, $1^{\text {st }}$ ed. New York: Mac Graw-Hill Publishing Company, 1 pp.

[14]. Omorogiwa, O., and Edeko, F. O. (2009). Investigation and Modelling of Power Received at $1800 \mathrm{MHz}$ in a Mountainous Terrain, International Journal of Electrical and Power Engineering. 129-135

[15]. Rama R., Balachander D, Tiwani, N. (2012). UHF short-range path loss measurement in forest and plantation environment for wireless sensor network, Communication Systems (ICCS), International conference, Singapore: 194-198.

[16]. RF Signal Tracker, Android Apps on Google; Retrieved from https://play.google.com, Retrieved $12^{\text {th }}$ November, 2012.

[17]. Roddy, D and Coolen J, (2003), Electronic Communications, $4^{\text {th }}$ ed. India: Prentice-Hall. 544-545pp. 